\title{
Uterine Leiomyomas Surgery: Assessment of Five Years in the Gynecology Department of Hôpital du Mali
}

\section{Mamadou Bakary Coulibaly ${ }^{1 *}$, Alassane Traoré1, Mody Abdoulaye Camara², Adama Sangaré1, Issa Ongoiba1, Mamadou Keïta ${ }^{3}$, Kalba Tembine ${ }^{4}$, Amadou Sidibé4, Ibrahim Teguete5, Youssouf Traore $^{5}$}

${ }^{1}$ Service of Gynecology of Hôpital du Mali, Bamako, Mali

${ }^{2}$ Service of Medical Imaging of Hôpital du Mali, Bamako, Mali

${ }^{3}$ Gynecology-Obstetrics Unit of Referral Health Center of Commune VI, Bamako, Mali

${ }^{4}$ Service of Anesthesia and Resuscitation of Hôpital du Mali, Bamako, Mali

${ }^{5}$ Service of Gynecology-Obstetrics Chu Gabriel Toure, Bamako, Mali

Email: ^mbccolby1@yahoo.com

How to cite this paper: Coulibaly, M.B., Traoré, A., Camara, M.A., Sangaré, A., Ongoiba, I., Keïta, M., Tembine, K., Sidibé, A., Teguete, I. and Traore, Y. (2021) Uterine Leiomyomas Surgery: Assessment of Five Years in the Gynecology Department of Hôpital du Mali. Open Journal of Obstetrics and Gynecology, 11, 1161-1171. https://doi.org/10.4236/ojog.2021.119110

Received: July 6, 2021

Accepted: September 12, 2021

Published: September 15, 2021

Copyright $\odot 2021$ by author(s) and Scientific Research Publishing Inc. This work is licensed under the Creative Commons Attribution International License (CC BY 4.0).

http://creativecommons.org/licenses/by/4.0/

\begin{abstract}
Uterine leiomyomas (myomas) are the most common benign tumors of the female genital tract. They affect $20 \%$ to $25 \%$ of women of childbearing age and are 3 to 9 times more common in black women. We initiated this study in order to report the socio-demographic aspects and the indications for leiomyomas surgery at Hôpital du Mali. This was a retro-prospective descriptive study, conducted in the gynecology department of Hôpital du Mali from January 1, 2015 to December 31, 2019. Any patients, regardless of their age, in whom a leiomyomas had been detected and surgically treated were included. We had collected 180 cases of surgery for leiomyomas out of 950 surgical procedures, with a frequency of $18.94 \%$. The $36-45$ age group represented $45 \%$ of our patients with an average age of 35 years. Nulligravida accounted for $48.9 \%$ and nulliparous $(60 \%)$. The main reason for consultation was the desire to become pregnant (53.33\%). A history of myomectomy was found out in $15.55 \%$ of patients. Pelvic ultrasound figured out $64.44 \%$ interstitial myomas. Myomectomy was performed in $88.88 \%$ of cases and hysterectomy in $11.12 \%$ of cases. Among our patients $39.37 \%$ had become pregnant. Operative complications were dominated by anemia $14.44 \%$. Leiomyoma was the histological tissue found in all cases of myomectomy. The average duration of hospitalization was 3 days. Conclusion: Leiomyomas surgery is the first scheduled gynecological surgical activity. Laparotomy remains the primary route of entry. The indications are dominated by the desire for pregnancy.
\end{abstract}




\section{Keywords}

Uterine Leiomyomas, Surgery, Hôpital du Mali

\section{Introduction}

Myomas are common benign gynecologic tumors of the female genital tract. They affect $20 \%$ to $25 \%$ of women of childbearing age and are 3 to 9 times more common in black women than in white women [1]. They usually appear after the age of 30 [1] [2]. However, the pathogenesis remains unclear today. Their occurrence and growth are influenced by many factors including: estrogens, progestins, growth factors, angiogenesis, genetic predisposition, nulliparity, obesity and precocity of menarche [3] [4].

Leiomyomas are often asymptomatic, detected during a routine pelvic exam or during pelvic imaging. They can be developed by menometrorrhagia, heaviness, pelvic pain, a feeling of lumpiness. It may be a matter of infertility [5].

They are usually small in size, ranging from a few millimeters to several centimeters, often asymptomatic. Uterine leiomyomas can (UL) have larger dimensions that can reach several decimeters. Leiomyomas are now a real public health issue [5]. The excessive volume of certain fibroids, the delay in diagnosis and even the reluctance of certain patients to use conventional medicine lead to difficulty in the various methods of treatment [4]. However, the data from Mali are relatively few and we have therefore attempted here to characterize the surgery for myomas at the hospital in Mali. We believe that the data can be useful in practice and policy making in this area and can also be generalized to African countries.

We initiated this work in order to report the socio-demographic and therapeutic aspects of fibroids.

\section{Methodology}

This was a retro-prospective descriptive study of data collection. The study was carried out in the gynecology department of Hôpital du Mali from January 1, 2015 to December 31, 2019. Any patients in whom, leiomyomas had been detected and who had undergone surgery were included in our study. The variables studied were: socio-demographic (age, marital status, occupation), gyneco-obstetrics (parity, gestity), clinical (menstrual cycle disorders, pelvic pain, pelvic masses, desire for pregnancy), imaging (pelvic ultrasound), gynecological examination (vaginal examination, abdominal palpation, uterine height measurement), surgery data (operating time, type of anesthesia, type of surgery, preoperative and postoperative complications), preoperative biological assessment.

All of our patients had previously benefited from a gynecological consultation which also measured uterine height with a tape measure. This measurement was 
evaluated in centimeters before surgery. The gynecological examination was supplemented by visual inspection techniques of the cervix using acetic acid speculum and Lugol (IVA/IVAL) as part of cervical cancer screening. Gonadotropin releasing hormone ( $\mathrm{GnRh}$ ) antagonists for the medical treatment of volumetric reduction of myomatous nuclei had been prescribed in some patients. All patients had received a pelvic ultrasound to assess the size and mapping of the myomas.

Those who received GnRh treatment had undergone a second ultrasound as a comparison with the first. A preoperative biological assessment including: rhesus grouping, blood count, glycemia, creatinemia, coagulation assessment (times: bleeding, coagulation, cephalin kaolin), uricemia and retroviral serology.

Surgical decisions were made on the basis of: excessive uterine size, menometrorrhagia and desire for pregnancy. All the surgeries were performed by laparotomy, with sub-umbilical incisions, pfannenstiel or median type. A tourniquet was placed at the level of the uterine isthmus to minimize intraoperative bleeding.

The measurements of the myomatous nuclei and/or the uterus were evaluated postoperatively.

They were all seen in a pre-anesthetic consultation.

Our data was collected on an individual survey sheet, from patient files, the operative report register, and the anatomo-pathological result.

\section{Results}

We had collected 180 cases of surgery for leiomyoma out of 950 gyneco-obstetrical procedures, or a frequency of $18.94 \%$. The 36 - 45 age group represented $45 \%$ of our patients. The mean age was 35 with extremes of 20 to 55 . Nulligravida accounted $48.9 \%$ and nulliparous (60\%). The main reasons for consultation were the desire to become pregnant (53.33\%) and genital haemorrhage (35.55\%). The history of myomectomy and familial fibroma concerned respectively $15.55 \%$ and $13.33 \%$ of our patients. Dysmenorrhea was pointed out in $57.8 \%$ of patients. Among our patients $35.6 \%$ had had menarche at 15 years. The main topographies of myomas on ultrasound were: interstitial (64.44\%), submucosal (23.88\%), subserous (6.68\%) and intracavitary (5\%). Hysterosalpingography (HSG) was performed in $10.56 \%$ of patients and $49.44 \%$ had received GnRH hormone therapy for the volumetric reduction of myomas (Table 1). Polymyomectomy (PMM) was performed in $88.88 \%$ of cases (Figure 1 ) and hysterectomy in $11.12 \%$ of cases (Figure 2). This PMM was performed without opening the uterine cavity (65\%); and brought back multiple nuclei (90\%) and single in $10 \%$ of cases (Figure 3). The size of the post myomectomy nuclei was less than $6 \mathrm{~cm}$ in 52.5\% of cases. Spinal anesthesia was performed (96.7\%); and the incision was of the pfannenstiel type (88.9\%) (Figure 4). The duration of the operation was two (2) hours in $79.5 \%$. Blood transfusion concerned $12.22 \%$. Operative complications were dominated by anemia (14.44\%) and parietal 
Table 1. Maternal characteristics.

\begin{tabular}{|c|c|c|}
\hline Maternal characteristics & Number & Percentage \\
\hline \multicolumn{3}{|l|}{ Age (average age: 35 ) } \\
\hline - $\quad 25$ - 35 years old & 80 & 44.44 \\
\hline - $\quad 36$ - 45 years old & 81 & 45 \\
\hline - $\quad 46$ - 55 years old & 19 & 10.60 \\
\hline \multicolumn{3}{|l|}{ Gestity } \\
\hline - $\quad$ Nulligravida & 88 & 48.9 \\
\hline - Primigravida & 44 & 24.4 \\
\hline - $\quad$ Multigravida & 48 & 26.7 \\
\hline \multicolumn{3}{|l|}{ Parity } \\
\hline - Nulliparous & 108 & 60 \\
\hline - Primiparous & 36 & 20 \\
\hline - $\quad$ Multiparous & 36 & 20 \\
\hline \multicolumn{3}{|l|}{ Reason for consultation } \\
\hline - Desire for pregnancy & 96 & 53.33 \\
\hline - $\quad$ Genital bleeding & 64 & 35.55 \\
\hline - Pelvic mass/gravity & 20 & 11.12 \\
\hline - Hormone therapy (GnRH antagonists) & 89 & 49.44 \\
\hline - History of myomectomy & 28 & 15.55 \\
\hline - Family history of fibroid & 24 & 13.33 \\
\hline \multicolumn{3}{|l|}{ Hysterosalpingography } \\
\hline - Yes & 19 & 10.56 \\
\hline - $\quad$ No & 161 & 89.44 \\
\hline \multicolumn{3}{|l|}{ Mapping of fibroids on ultrasound } \\
\hline - Interstitial & 116 & 64.44 \\
\hline - $\quad$ Submucosal & 43 & 23.88 \\
\hline - $\quad$ Under serous & 12 & 6.68 \\
\hline - Intra cavitary & 9 & 5 \\
\hline
\end{tabular}

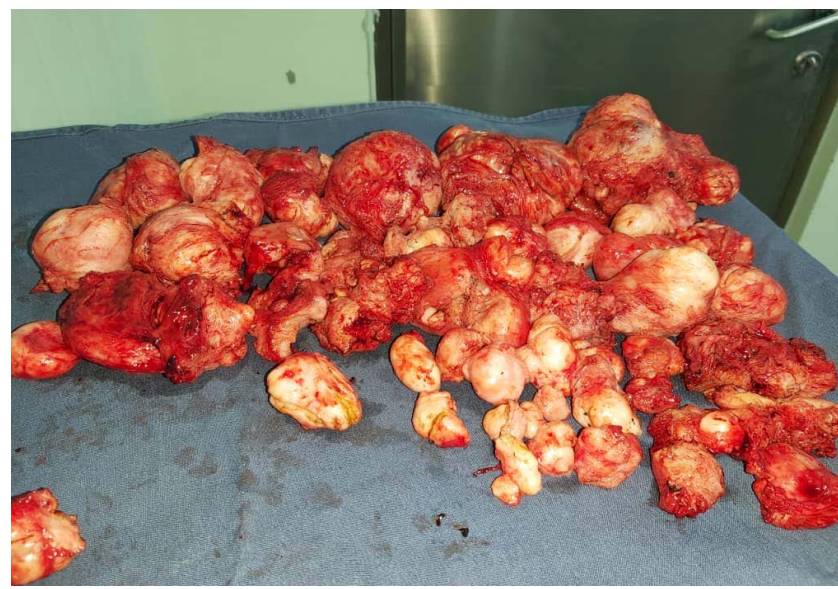

Figure 1. Polymyomectomy with preservation of the uterus. 


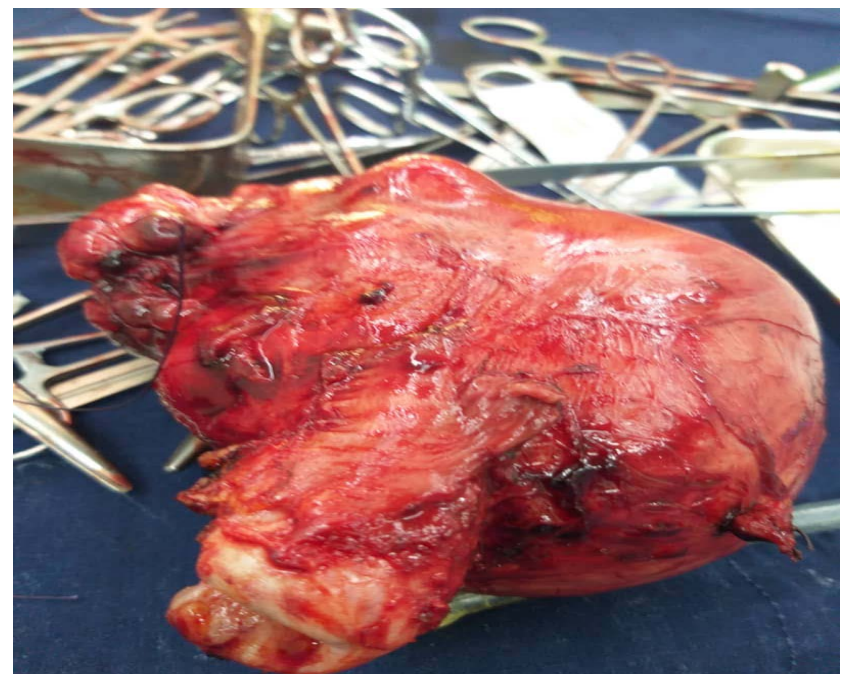

Figure 2. Total hysterectomy for polymyomatous uterus.

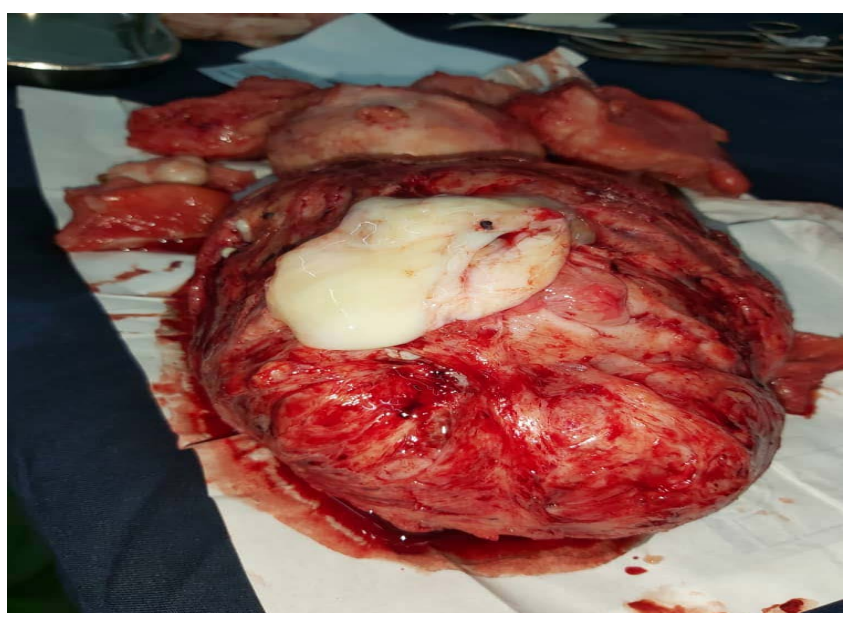

Figure 3. Single core myomectomy with omental adhesion.

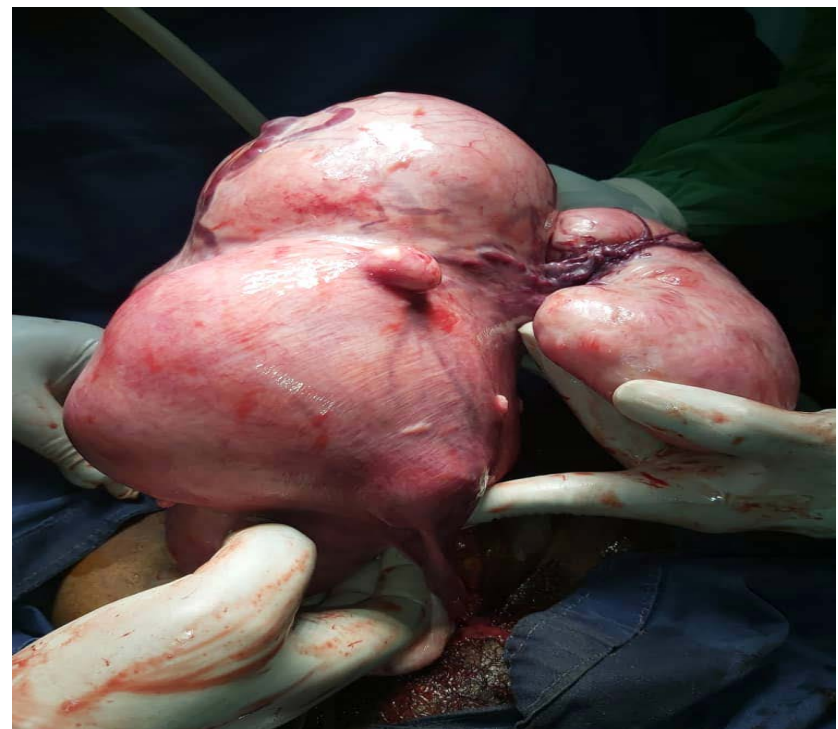

Figure 4. Globular uterus during surgery. 
suppurations (3.33\%) (Table 2). The histologic type was leiomyoma only. Among our patients (160/180) who underwent myomectomy, 63 had contracted pregnancy, i.e. a frequency of $39.37 \%$ (Table 3 ). Of the patients who had contracted a pregnancy, $88.88 \%$ had completed their pregnancies and $4.76 \%$ were premature births. They had all undergone a prophylactic cesarean section (Table 4). We had no known cases of placenta previa. The mean duration of hospital stay was 3 days.

Table 2. Surgical data.

\begin{tabular}{|c|c|c|}
\hline Surgical data & Number & Percentage \\
\hline \multicolumn{3}{|l|}{ Method of anesthesia } \\
\hline - Spinal anesthesia & 174 & 96.67 \\
\hline - General anesthesia & 6 & 3.33 \\
\hline \multicolumn{3}{|l|}{ Type of procedure } \\
\hline - Myomectomy & 160 & 88.88 \\
\hline - Hysterectomy & 20 & $11.12 \%$ \\
\hline \multicolumn{3}{|l|}{ Type of incision } \\
\hline - Pfannenstiel & 160 & 88.9 \\
\hline - Median & 20 & 11.1 \\
\hline \multicolumn{3}{|l|}{ Number of nuclei $(n=160)$} \\
\hline - Unique & 16 & 10 \\
\hline - Multiple & 144 & 90 \\
\hline \multicolumn{3}{|c|}{ Post myomectomy nuclei size $(n=160)$} \\
\hline$<6 \mathrm{~cm}$ & 84 & 52.5 \\
\hline$\geq 6 \mathrm{~cm}$ & 76 & 47.5 \\
\hline \multicolumn{3}{|l|}{ Cavity invasion $(n=160)$} \\
\hline Yes & 56 & 35 \\
\hline No & 104 & 65 \\
\hline \multicolumn{3}{|l|}{ Transfusion } \\
\hline Yes & 22 & 12.22 \\
\hline No & 158 & 87.78 \\
\hline Postoperative complications & 26 & 14.44 \\
\hline Anemia & 6 & 3.33 \\
\hline
\end{tabular}

Table 3. Post-myomectomy pregnancy conception.

\begin{tabular}{ccc}
\hline Pregnancy conception & Number & Percentage \\
\hline Yes & 63 & 39.37 \\
No & 97 & 60.63 \\
Total & 160 & 100 \\
\hline
\end{tabular}


Table 4. The fate of post-myomectomy pregnancies.

\begin{tabular}{|c|c|c|c|}
\hline \multicolumn{2}{|c|}{ the future of pregnancy } & Effective & Percentage \\
\hline \multicolumn{2}{|c|}{ full term } & 56 & 88.88 \\
\hline \multicolumn{2}{|c|}{ Abortion } & 3 & 4.76 \\
\hline \multicolumn{2}{|c|}{ ectopic pregnancy } & 1 & 1.59 \\
\hline \multirow{3}{*}{ prematurity } & newborn alive & 1 & 1.59 \\
\hline & full term & 2 & 3.18 \\
\hline & Total & 63 & 100 \\
\hline
\end{tabular}

\section{Discussions}

The limitations of our study were: the loss of vision in some patients and the lack of laparoscopic equipment for the myomectomy.

1) Frequency: During the study period, we collected 180 cases of surgery for leiomyoma out of 950 gyneco-obstetric procedures, with a frequency of $18.94 \%$. Our data were higher than the $13.56 \%$ of Ahmadou et al. [6] at the National Hospital of Point G/Mali; but clearly lower than those reported by ABD Koffi [7] in Abidjan (53.65\%).

2) Age: The mean age of our patients was 35 years old. Our data were comparable with those of Rakotomahenina $\mathrm{H}$ [8] in Bordeaux/France and Bang Ntamack JA [9] in Gabon who respectively reported a mean age of 35 and 34.9 years. They were less than the 37.5 years reported by ABD Koffi [7].

3) The main reasons for consultations were the desire to become pregnant (53.33\%) and menometrorrhagia (35.55\%). Nourelhouda C [10] mainly reported menometrorrhagia (35\%) and pelvic pain (24.98\%). ABD Koffi [7] reported menometrorrhagia (52.6\%), pelvic pain mass (31.8\%) and infertility (15.6\%). In the series of Ahmadou C [6], desire for a child (75.85\%), followed by pelvic pain (21.34\%) and bleeding (2.81\%) were the main reasons for consultations. We do not have all the data on the fate of all the patients operated on, due to loss of sight after myomectomy.

4) The antecedents: The nulligravida concerned $48.9 \%$ of our patients. Our figures were higher than those reported by Ahmadou C [6] (38.76\%) and Bang Ntamack JA (33.5\%) [9].

Nulliparity was $60 \%$ of our patients and multiparity $20 \%$. Our data were different from those of Nourelhouda C [10] who reported $37.83 \%$ of nulliparous and $26.57 \%$ of multiparous. In the series of ABD Koffi [7] and Rakotomahenina $\mathrm{H}$ [8], nulliparity concerned $70.4 \%$ and $36 \%$ of patients respectively. This distribution according to parity revealed an increase in this type of pathology in nulliparous women.

5) The history of myomectomy affected $15.55 \%$ of patients. This rate was higher than $8.43 \%$ of Ahmadou [6] in Bamako and 3.71\% of Nourelhouda C [10] in Algeria.

We found out a family history of leiomyoma in $13.33 \%$ of our patients and $86.67 \%$ had no information on this issue. In our series, $35.6 \%$ of the patients had 
had menarche at 15 years whereas in the study of Nourelhouda C [10] it was 12 years old in $60.3 \%$ of patients. The early menarche was a risk factor for leiomyoma in the study of Nourelhouda C [10].

6) Hormone therapy: GnRH antagonists had been administered in $49.44 \%$ of our patients before surgery, as part of the volumetric reduction of myomas. The use of GnRH analogues for 3 to 4 months before a leiomyoma surgery reduces the volume of the uterus and the size of the fibroids [11]. The use of GnRH analogues preoperatively will reduce the volume of myomas, genital hemorrhages and operative bleeding [11] [12]. In our study, we found that there is little bleeding during the operation for patients who received this hormone therapy.

7) Data from para-clinical examinations: All our patients had at least one ultrasound report. The main locations of myomas on pelvic ultrasound were: interstitial (64.44\%), submucosal (23.88\%) subserous (6.68\%) and intracavitary (5\%). Our data were different from those of Nourelhouda C [10] who reported: subserous (43\%), submucosal (34\%) and intramural (23\%) myomas. Bang Ntamack JA [9] reported interstitial (34.7\%), submucosal (26.7\%) and intramural (19.8\%) myomas. In the study by Rakotomahenina $\mathrm{H}$ [8], the locations were: intramural (42\%), submucosal (39\%) submucosal (19\%). HSG has been requested in a situation of desire for pregnancy to assess the patency of the tubes and the shape of the uterine cavity. The presence of a submucosal or interstitial myoma, a fortiori, deforming the uterine cavity, would have a deleterious effect on the conception of a pregnancy and its course in the intrauterine. However, only $10.56 \%$ of our patients had undergone HSG. Our figures are lower than those of Ahmadou C [6] who reported that $49 \%$ of his patients. This difference can be explained by the fact, that the majority of our patients had painful prejudices about HSG, on the one hand and on the other hand the continuous genital hemorrhages.

8) Surgical data: PMM was performed in $88.88 \%$ of our patients and hysterectomy in $11.12 \%$ of cases. Our data were different from those of Nourelhouda C [10] who reported $71.82 \%$ myomectomy and 28.18 hysterectomy. In the study of ABD Koffi [7], myomectomy affected $70.4 \%$ of patients and hysterectomy $29.6 \%$. Our PMMs were performed in $65 \%$ of cases without invasion of the uterine cavity. This rate was higher than $42 \%$ in the series by Rakotomahenina $\mathrm{H}$ [8].

Of the 160 patients who underwent myomectomy, 90\% had multiple nuclei. Nourelhouda C [10] and Rakotomahenina H [8] reported multiple nuclei respectively in $63.46 \%$ and $31 \%$ of cases. Regarding the size of the myomas, $52.5 \%$ were less than $6 \mathrm{~cm}$ in our series. Our figures are higher than those of Rakotomahenina H [8] (34\%) but lower than those of Nourelhouda C [10] (70.99\%).

There are hysteroscopic, laparoscopic and vaginal routes. We report that all of our interventions were performed by laparotomy as in the studies of ABD Koffi [7], Nourelhouda C [10] and H. Foulot [13] in France. However, in the series of E Daraï [14], all myomectomies were performed laparoscopically. Doumbia Y [15] had used the laparoscopic route in $65.2 \%$ of patients, laparotomy $33.3 \%$ and 
the vaginal route $1.5 \%$.

The incision was pfannenstial in $88.9 \%$ of our patients. Our data were comparable to those of ABD Koffi [7], Rakotomahenina $\mathrm{H}$ [8] and Nourelhouda C [10] where the pfannenstiel and median incisions were the most used. In the Ojabo AO series [16], all incisions were pfannenstiel.

9) Anesthesia: Spinal anesthesia affected $96.7 \%$ of patients, unlike the study of E Darai [14]; who had performed general anesthesia because of the laparoscopic route.

The mean duration of the operation was two (2) hours (79.5\%); as well as the study by ABD Koffi [7].

10) Complications and postoperative care: blood loss had been minimized according to our findings, by placing a tourniquet at the isthmus. This technique made it possible to reduce bleeding during the extraction of the nuclei, thus limiting blood transfusions, which were $12.22 \%$. Operative complications were dominated by anemia (14.44\%) and parietal suppurations (3.33\%). The average duration of hospitalization was 3 days; the same observation was made by ABD Koffi [7]. Leiomyoma was the histological tissue found in all of our patients. Our results can be compared to those of the other authors.

11) Conception of post-myomectomy pregnancy: We had recorded $39.37 \%$ of cases of post-myomectomy pregnancy. Among our patients (60/63 or 95.23\%) who had contracted pregnancy post myomectomies were caesarized. We had collected three (3) cases of spontaneous abortion and one case of ectopic pregnancy having undergone laparotomy.

Our data were similar to those of Rakotomahenina $\mathrm{H}$ [8] (38.8\%) and lower than that of Bang Ntamack JA [9] (21.8\%). G Legendre [17] affirmed that the pregnancy rates were similar in the event of myomectomy by laparotomy and laparoscopy.

Current data have not provided new scientific findings; however, the description of area-specific data can be useful in future practice and also in the development of health policies.

\section{Conclusion}

Leiomyoma surgery is the first gynecological surgical activity scheduled at Hôpital du Mali. Laparotomy remains the primary route of entry because of the size and high number of myomatous nuclei. The indications are dominated by the desire for pregnancy and genital hemorrhages. It would be necessary to develop an awareness project and early detection of leiomyoma, in order to reduce the rate of surgical treatment and female infertility.

\section{Author Approval}

All authors agree to the submission of this article.

\section{Consent}

For this work we received the consent of the patient; that of the department head 
and the director of the Hôpital du Mali.

\section{Conflicts of Interest}

The authors have declared no conflicts of interest.

\section{References}

[1] Okogbo, F.O., Ezechi, O.C., Loto, O.M. and Ezeobi, P.M. (2011) Uterine Leiomyomata in South Western Nigeria: A Clinical Study of Presentations and Management Outcome. African Health Sciences, 11, 271-278.

[2] Baird, D.D., Dunson, D.B., Hill, M.C., Cousins, D. and Schectman, J.M. (2003) High Cumulative Incidence of Uterine Leiomyoma in Black and White Women: Ultrasound Evidence. American Journal of Obstetrics and Gynecology, 188, 100-107. https://doi.org/10.1067/mob.2003.99

[3] Racinet, C. (2009) Epidemiology, Risk Factors and Symptomatology of Uterine Myomas. MT Medicine of Gynecology Endocrinology Reproduction, 11, 118-122.

[4] Flake, G.P. andersen, J. and Dixon, D. (2003) Etiology and Pathogenesis of Uterine Leiomyomas: A Review. Environmental Health Perspectives, 111, 1037-1054. https://doi.org/10.1289/ehp.5787

[5] Wallach, E.E. and Vlahos, N.F. (2004) Uterine Myomas: An Overview of Development, Clinical Features and Management. Journal of Obstetrics and Gynaecology, 104, 393-406. https://doi.org/10.1097/01.AOG.0000136079.62513.39

[6] Coulibaly, A., Sima, M., Traoré, M.S., et al. (2020) The Place of Uterine Fibroid in Patients Who Consult for Infertility the Service of Gynecology-Obstetrics of THC Point G. Malian Review of Science and Technology, 1, 18-24.

[7] Koffi, A.B.D., Olou, N.L., Fomba, M., Séni, K., Horo, A. and Touré-Ecra, A.F. (2013) Surgery of Uterine Fibroids: Assessment of Five Years of Activity in the Gynecology Department of the THC of Yopougon (Abidjan). Rev IntSc Med, 15, 95-99.

[8] Rakotomahenina, H., Rajaonarison, J.J.C. andrianampy, H., Randriambelomanana, J.A., Brun, J. and Hocke, G. (2016) Evaluation of the Obstetric Prognosis after Myomectomy in the Obstetric Gynecology Department of CHU Bordeaux. Malagasy Journal of Gynecology-Obstetrics, 2, 19-24.

[9] Bang Ntamack, J.A., Mayi-Tsonga, S., Sima Ole, B. and Meye, J.F. (2009) Pregnancy after Myomectomy in Libreville, Gabon. Clinic of Mother Child Health, 6, 1101-1106.

[10] Chalal, N. and Demmouche, A. (2013) Epidemiological Profile of Uterine Fibroids in the Region of SidiBel Abbes, Algeria. Pan African Medical Journal, 15, 7.

[11] Lethaby, A., Vollenhoven, B. and Sowter, M.C. (2001) Pre-Operative GnRH Analogue Therapy before Hysterectomy or Myomectomy for Uterine Fibroids. Cochrane Database of Systematic Reviews, No. 2. CD000547. https://doi.org/10.1002/14651858.CD000547

[12] Friedman, A.J., Hoffman, D.I., Committee, F., Browneller, R.W. and Miller, J.D. (1991) Treatment of Leiomyomata Uteri with Leuprolide Acetate Depot: A DoubleBlind, Placebo-Controlled, Multicenter Study. The Leuprolide Study Group. Obstetrics \& Gynecology, 77, 720-725.

[13] Foulot, H., Chopin, N., Malartic, C., Fauconnier, A. and Chapron, C. (2005) Myomectomies by Laparotomy. EMC-Obstetrics Gynecology, 2, 377-383.

https://doi.org/10.1016/j.emcgo.2005.08.001

[14] Daraï, E., Dessolle, L., Poncelet, C., Omnes, S., Soriano, D., Benifla, J.-L. and Made- 
lenat, P. (2001) Laparoscopic Myomectomy: Critical Analysis of a Nine-Year Experience. The Gynecologist's Letter, 263, June 2001.

[15] Doumbia, Y., Hocke, C., Djanhan, Y., N'guessan, K., Bokossa, M. and Prat-Balagna (2004) laparoscopic Myomectomy: Experience of the Gynecology Department of SAINT ANDRE DE BORDEAUX Hospital. Mali Medical, T XIXN, 37-38.

[16] Ojabo, A.O., Adesiyun, A.G., Hembah-Hilekaan, S.K., Ameh, N., Umar, H. and Mohammed-Durosinlorun, A. (2015) Experience with Pfannenstiel Incision for Very Large Uterine Fibroids. International Journal of Advances in Case Reports, 2, 359-362.

[17] Legendre, G., Brun, J.-L. and Fernandez, H. (2011) Place of Myomectomies in Spontaneous Conception or in Women Wishing to Preserve Their Fertility. Journal of Obstetric Gynecology and Reproductive Biology, 40, 875-884.

https://doi.org/10.1016/j.jgyn.2011.09.023 